\title{
Argon Plasma Coagulation for a Bleeding Gastrointestinal Stromal Tumor
}

\author{
Harunobu Kawamura $^{\text {a }}$ Masahiko Inamori ${ }^{\text {a }}$ Tomoyuki Akiyama $^{\text {a }}$ Keiko Akimoto $^{\text {a }}$ \\ Koji Fujita $^{a}$ Hirokazu Takahashi $^{\mathrm{a}}$ Masato Yoneda ${ }^{\mathrm{a}}$ Yasunobu Abe $^{\mathrm{a}}$ Kensuke Kubota $^{\mathrm{a}}$ \\ Norio Ueno ${ }^{a}$ Yoshiaki Inayama $^{b}$ Hiroshi Haradac Yasushi Rino $^{c}$ Atsushi Nakajima ${ }^{a}$ \\ ${ }^{a}$ Gastroenterology Division and Departments of b Pathology and ' Surgery, Yokohama City University School of \\ Medicine, Yokohama, Japan
}

Dear Sir,

A gastrointestinal stromal tumor (GIST) occurs submucosally in the stomach and endoscopically represents an unusual cause of upper gastrointestinal bleeding. Endoscopic hemostasis has sometimes proved to be difficult in bleeding GISTs.

A 65-year-old woman was admitted to our hospital complaining of tarry stools. A subsequent endoscopic examination revealed that there was a submucosal tumor in the lower body of the stomach. Endoscopy revealed hemorrhage from ulceration. Argon plasma coagulation (APC) was performed, resulting in successful en- doscopic hemostasis (fig. 1). Following the procedure, laparoscopic surgery was performed, and the pathological diagnosis was GIST.

APC in endoscopy was first described in 1986 and became a major treatment of choice for gastrointestinal hemorrhage in superficial lesions such as gastric antral vascular ectasia, red veins in the esophagus, and angiodysplasia. Our case showed steady bleeding from the top of the GIST, but the vessel responsible for the bleeding could not be identified. We confirm the validity of APC for the treatment of a bleeding GIST.

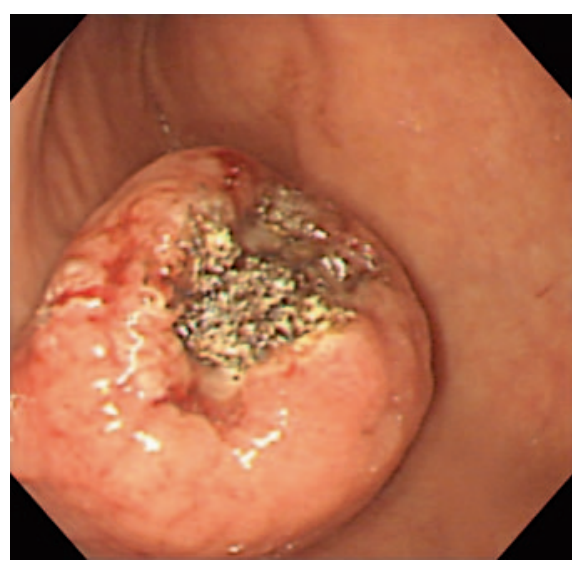

Fig. 1. APC was performed for a bleeding gastric submucosal tumor, resulting in successful endoscopic hemostasis.

\section{KARGER}

Fax +41613061234 E-Mail karger@karger.ch www.karger.com
Masahiko Inamori

Gastroenterology Division, Yokohama City University School of Medicine

3-9 Fukuura, Kanazawa-ku

Yokohama 236-0004 (Japan)

Tel. +81 45787 2640, Fax +81 45784 3546, E-Mail inamorim@yokohama-cu.ac.jp 